\title{
Lower levels of plasma 25-hydroxyvitamin D among young adults at diagnosis of autoimmune type 1 diabetes compared with control subjects: results from the nationwide Diabetes Incidence Study in Sweden (DISS)
}

\author{
B. Littorin • P. Blom • A. Schölin • H. J. Arnqvist • \\ G. Blohmé • J. Bolinder • A. Ekbom-Schnell • \\ J. W. Eriksson • S. Gudbjörnsdottir • L. Nyström • \\ J. Östman • G. Sundkvist
}

Received: 23 April 2006 / Accepted: 19 July 2006 / Published online: 27 October 2006

(C) Springer-Verlag 2006

\begin{abstract}
Aims/hypothesis Low plasma vitamin D concentrations may promote the development of type 1 diabetes. To test this hypothesis, we measured plasma 25 -hydroxyvitamin D (25OHD) in young adults with type 1 diabetes.

Methods The nationwide Diabetes Incidence Study in Sweden (DISS) covers 15- to 34-year-old people with newly diagnosed diabetes. Blood samples at diagnosis were collected during the 2-year period 1987/1988. Patients with islet antibodies (islet cell antibodies, GAD antibodies or
\end{abstract}

B. Littorin · G. Sundkvist

Department of Clinical Sciences, University of Lund,

Malmö University Hospital,

Malmö, Sweden

B. Littorin $(\square)$

Södervärn Primary Health Care Centre,

Bangatan 11, S-214 26 Malmö, Sweden

e-mail: bengt.littorin@med.lu.se

P. Blom

Electra-Box Diagnostica,

Tyresö, Sweden

\author{
A. Schölin \\ Department of Medical Science, Uppsala University, \\ Uppsala, Sweden
}

H. J. Arnqvist

Department of Internal Medicine, Faculty of Health Sciences,

University of Linköping,

Linköping, Sweden

G. Blohmé

Department of Internal Medicine, Söder Hospital,

Stockholm, Sweden tyrosine phosphatase-like protein antibodies) were defined as having autoimmune type 1 diabetes. Plasma 25OHD was measured in samples taken from 459 patients at the time of diagnosis, and in 138 of these subjects 8 years later. The results were compared with age- and sex-matched control subjects $(n=208)$.

Results At diagnosis, plasma 25OHD levels were significantly lower in patients with type 1 diabetes than in control subjects $(82.5 \pm 1.3$ vs $96.7 \pm 2.0 \mathrm{nmol} / 1 ; p<0.0001)$. Eight years later, plasma $25 \mathrm{OHD}$ had decreased in patients

\section{J. Bolinder $\cdot$ J. Östman \\ Department of Endocrinology, \\ Metabolism and Diabetes, \\ Karolinska University Hospital, \\ Huddinge, Sweden}

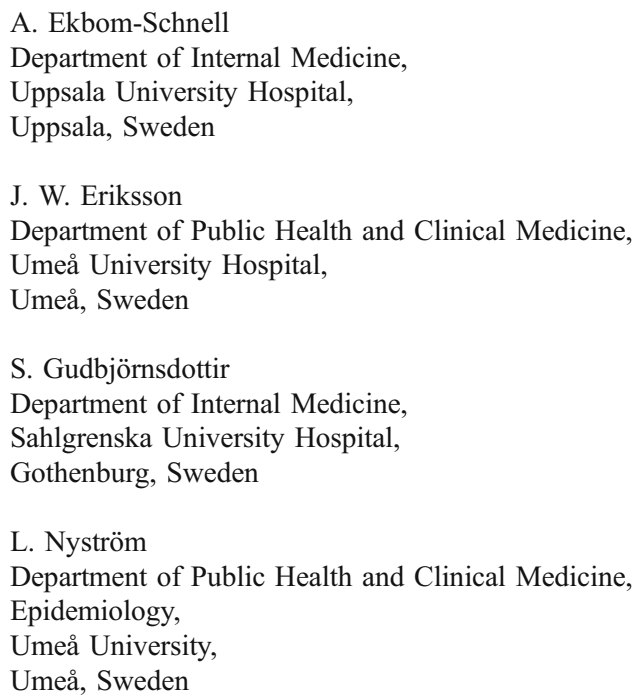

A. Ekbom-Schnell

Department of Internal Medicine,

Uppsala University Hospital,

Uppsala, Sweden

J. W. Eriksson

Department of Public Health and Clinical Medicine,

Umeå University Hospital,

Umeå, Sweden

S. Gudbjörnsdottir

Department of Internal Medicine,

Sahlgrenska University Hospital,

Gothenburg, Sweden

L. Nyström

Department of Public Health and Clinical Medicine,

Epidemiology,

Umeå University,

Umeå, Sweden 
$(81.5 \pm 2.6 \mathrm{nmol} / \mathrm{l} ; p=0.04)$. Plasma 25OHD levels were significantly lower in diabetic men than in diabetic women at diagnosis $(77.9 \pm 1.4 \mathrm{vs} 90.1 \pm 2.4 \mathrm{nmol} / \mathrm{l} ; p<0.0001)$ and at follow-up (77.1 $\pm 2.8 \mathrm{nmol} / 1$ vs $87.2 \pm 4.5 \mathrm{nmol} / 1 ; p=0.048)$. Conclusions/interpretation The plasma 25OHD level was lower at diagnosis of autoimmune type 1 diabetes than in control subjects, and may have a role in the development of type 1 diabetes. Plasma 25OHD levels were lower in men than in women with type 1 diabetes. This difference may be relevant to the high incidence of type 1 diabetes among young adult men.

Keywords 25-Hydroxyvitamin D 2 25OHD .

Autoimmunity · GADA · IA-2A · ICA · Islet antibodies ·

Type 1 diabetes $\cdot$ Vitamin $\mathrm{D}$

$\begin{array}{ll}\text { Abbreviations } \\ \text { 25OHD } & \text { 25-hydroxyvitamin D } \\ \text { DISS } & \text { Diabetes Incidence Study in Sweden } \\ \text { GADA } & \text { GAD antibodies } \\ \text { IA-2 } & \text { tyrosine phosphatase-like protein } \\ \text { IA-2A } & \text { tyrosine phosphatase-like protein antibodies } \\ \text { ICA } & \text { islet cell antibodies }\end{array}$

\section{Introduction}

Type 1 diabetes is an autoimmune disease and environmental factors contribute to its development [1]. Vitamin D has been associated with type 1 diabetes [2]. Several studies suggest that vitamin D supplementation in early childhood decreases the risk of developing type 1 diabetes [3-5]. Moreover, there is an inverse correlation between vitamin D intake during pregnancy and the presence of islet antibodies in the offspring [6]. This observation suggests an immunological mechanism behind the association between vitamin $\mathrm{D}$ and type 1 diabetes. The immunological concept has support from the finding of 1,25-hydroxyvitamin $D_{3}$ receptors on monocytes and activated $\mathrm{T}$ cells [7]. Also, polymorphism in the vitamin $\mathrm{D}$ receptor gene has been shown to be associated with susceptibility to type 1 diabetes [8]. The biologically active form of vitamin D may be a modulator of the immune system [9]. Chemokines produced by beta cells recruit pathogenic [10] and regulatory $\mathrm{T}$ cells [11]. A vitamin $\mathrm{D}$ analogue has been shown to downregulate the production of proinflammatory chemokines, thereby inhibiting $\mathrm{T}$ cell recruitment and the development of type 1 diabetes in NOD mice [12]. Vitamin $\mathrm{D}$ deficiency may promote beta cell destruction in humans. Nutritional status with respect to vitamin D is best represented by the circulating concentration of plasma 25-hydroxyvitamin D (25OHD) [13].
There is a high incidence of type 1 diabetes, with a clear male preponderance, among young adults in Sweden [14]. Associations between mean temperature and latitude versus the incidence of type 1 diabetes [15] favour a correlation between sunlight and type 1 diabetes. Latitude can dramatically affect the production of vitamin $\mathrm{D}_{3}$ in the skin. This implies an association between sunshine and type 1 diabetes, and vitamin D may be the connection. The higher incidence of type 1 diabetes among men as compared with women in Sweden may be related to differences in vitamin $\mathrm{D}$ metabolism or sensitivity between sexes.

To assess whether there is an association between vitamin $\mathrm{D}$ and autoimmune type 1 diabetes in young adults, we measured plasma 25OHD at the time of diagnosis of autoimmune type 1 diabetes and at follow-up 8 years later. The aim was to test the hypothesis that low plasma vitamin D concentrations are associated with the development of type 1 diabetes in young adults, particularly males.

\section{Subjects and methods}

Since 1983 , all newly diagnosed 15 - to 34 -year-old patients with diabetes mellitus in Sweden have been registered prospectively in the nationwide population-based Diabetes Incidence Study in Sweden (DISS) [16]. During a 2-year period (1987/1988), at the time of DISS registration, soon after diagnosis, patients were asked to donate a blood sample for measurement of islet antibodies [17]. Control subjects matched with the probands for age (born on the same day), sex and residence (living in the same county) were also asked to donate blood samples. Samples were taken at random (in terms of time of day) and plasma was collected in EDTA and sent unfrozen by surface mail to a central laboratory. Plasma was frozen at $-20^{\circ} \mathrm{C}$ and stored until analysis. During the 2-year period, plasma samples at the time of diagnosis were obtained from $636(76 \%)$ of 839 registered patients (Fig. 1) and islet antibodies were found in $82 \%$ (521 of 636). Among patients with islet antibodies, plasma for determination of $25 \mathrm{OHD}$ was available from $88 \%$ (459 of 521). Eight years later, all patients were invited to a follow-up study and 312 with islet antibodies at diagnosis accepted [18]. Out of these, a follow-up sample was available in 138 patients (44\%) for 250HD assessment. Plasma samples at follow-up were taken at a median of 8.6 years (range 3.1) after diagnosis. Of the 1,678 control subjects recruited for the study, $280(17 \%)$ donated plasma samples and 208 were available for $250 H D$ measurement. Participation rates of patients and control subjects are given in Table 1. Assessment of 250HD was conducted 16-17 years after the diagnosis of diabetes, 7-8 years after 


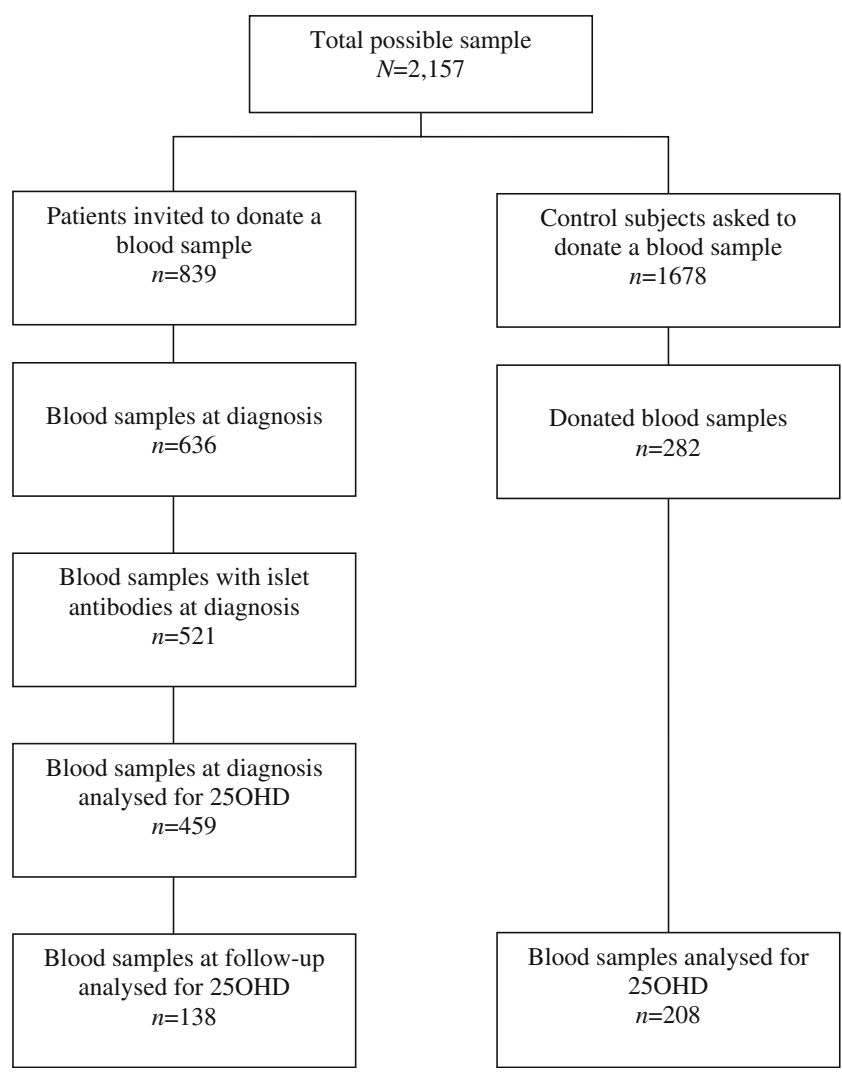

Fig. 1 Flowchart of blood samples in the DISS $87 / 88$ cohort at diagnosis and follow-up

follow-up in patients and 16-17 years after sampling in control subjects.

Laboratory assays

Islet cell antibodies (ICA) were determined by a prolonged immunofluorescence assay [19]. GAD antibodies (GADA) [20] and tyrosine phosphatase-like protein antibodies (IA-2A) [21] were determined by radioligand binding assay based on ${ }^{35} \mathrm{~S}$-methionine labelled human recombinant in vitro transcribed-translated GAD65 and IA-2, respectively. For the patients from whom a blood sample was taken at follow-up, $\mathrm{HbA}_{1 \mathrm{c}}$ was measured by an HPLC method [22]. The normal reference interval was 4.0-5.2\%. Different 25OHD assays yield markedly different results [23]. In this study, all analyses were done in the same assay. The plasma concentration of 250HD was measured by the Nichols Advantage 25OHD assay [24]. This assay is based on chemiluminescence detection and vitamin $\mathrm{D}$ binding protein for competitive displacement. The reference range was $25-170 \mathrm{nmol} / 1$ and the detection limit $10 \mathrm{nmol} / 1$ (4 $\mathrm{ng} / \mathrm{ml})$. Reproducibility from four different pools with ranges of 27.5-145 nmol/1 yielded a within-run $\mathrm{CV}$ of $4.5-3.6 \%$; the total $\mathrm{CV}$ was $7.8 \%$. On repeated thawing there was a slight but insignificant increase in the concentration of 25OHD with increasing numbers of thawings, as also shown by others [25].

Statistical analysis

The paired $t$ test was used to test for differences between the baseline and follow-up samples, and Student's $t$ test (for normally distributed data) or the Mann-Whitney $U$ test (for non-normally distributed data) were used for comparisons between patients with diabetes and control subjects. As the plasma 25OHD level covaries with BMI, correction was made by univariate analysis of variance. Differences in frequencies were evaluated with the $\chi^{2}$ test. Associations between variables were estimated by calculating Pearson's correlation coefficients or Spearman's $\rho$. Significance was accepted for $p$ values $<0.05$. Data were analysed using SPSS (Chicago, IL, USA). Results are reported as means \pm SEM.

\section{Results}

\section{At time of diagnosis}

Patients were slightly younger than control subjects $(p=0.027)$ and, as expected, there was a male predominance among the patients (Table 2). Close to the time of diagnosis

Table 1 Participation rate and plasma 25OHD at diagnosis in young adults with autoimmune type 1 diabetes and control subjects in public health regions $1-6$ in Sweden (region 1 is the southernmost and region 6 the northernmost)

\begin{tabular}{|c|c|c|c|c|c|c|c|}
\hline & \multicolumn{6}{|c|}{ Public health region } & \multirow[t]{2}{*}{ Total } \\
\hline & 1 & 2 & 3 & 4 & 5 & 6 & \\
\hline \multicolumn{8}{|c|}{ Participation rate (\%) } \\
\hline Patients & 95 & 90 & 94 & 91 & 81 & 83 & 88 \\
\hline Control subjects & 21 & 20 & 29 & 12 & 18 & 29 & 22 \\
\hline \multicolumn{8}{|c|}{$25 \mathrm{OHD}(\mathrm{nmol} / \mathrm{l})(\mathrm{mean} \pm \mathrm{SEM})$} \\
\hline Patients & $80.4 \pm 3.5^{\mathrm{a}}$ & $83.6 \pm 3.5^{\mathrm{a}}$ & $82.7 \pm 3.7^{\mathrm{b}}$ & $78.1 \pm 2.4^{\mathrm{c}}$ & $85.6 \pm 3.1^{\mathrm{b}}$ & $87.8 \pm 5.1^{\mathrm{d}}$ & $82.5 \pm 1.3^{\mathrm{c}}$ \\
\hline Control subjects & $96.7 \pm 5.5$ & $97.5 \pm 4.9$ & $96.6 \pm 3.9$ & $99.1 \pm 4.5$ & $99.2 \pm 4.8$ & $89.7 \pm 5.3$ & $96.7 \pm 2.0$ \\
\hline
\end{tabular}

Test of difference between patients and control subjects: ${ }^{\mathrm{a}} p<0.05 ;{ }^{\mathrm{b}} p<0.01 ;{ }^{\mathrm{c}} p<0.001 ;{ }^{\mathrm{d}} p=0.48$ 
Table 2 Clinical characteristics and plasma 25OHD at diagnosis in young adults with type 1 diabetes vs control subjects (mean \pm SEM)

\begin{tabular}{|c|c|c|c|}
\hline Characteristic & $\begin{array}{l}\text { Patients } \\
(n=459)\end{array}$ & $\begin{array}{l}\text { Control subjects } \\
(n=208)\end{array}$ & $\begin{array}{l}\text { Test of difference } \\
\text { between patients } \\
\text { and controls ( } p \text { value) }\end{array}$ \\
\hline Males/females & 1.6 & 1.1 & 0.016 \\
\hline $\begin{array}{l}\text { Age (years) } \\
25 \mathrm{OHD}(\mathrm{nmol} / \mathrm{l})\end{array}$ & $24.4 \pm 0.3$ & $25.6 \pm 0.5$ & 0.027 \\
\hline All & $82.5 \pm 1.3$ & $96.7 \pm 2.0$ & $<0.0001$ \\
\hline Males & $77.9 \pm 1.4^{\mathrm{a}}$ & $93.9 \pm 2.7^{\mathrm{b}}$ & $<0.0001$ \\
\hline Females & $90.1 \pm 2.4$ & $99.7 \pm 2.9$ & 0.014 \\
\hline
\end{tabular}

Test of difference by sex: ${ }^{\mathrm{a}} p<0.0001 ;{ }^{\mathrm{b}} p=0.15$

of diabetes, plasma 25OHD levels were significantly lower in patients than in control subjects $(82.5 \pm 1.3$ vs $96.7 \pm 2.0 \mathrm{nmol} / \mathrm{l} ; p<0.0001$; Fig. 2). Amongst patients, the mean concentration of $25 \mathrm{OHD}$ was significantly lower in men than in women $(77.9 \pm 1.4$ vs $90.1 \pm 2.4 \mathrm{nmol} / \mathrm{l}$; $p<0.0001)$. Furthermore, the mean concentration of 25OHD was significantly $(p<0.0001)$ lower in diabetic men compared with control men, as well as in diabetic women compared with control women $(p=0.014)$. Amongst control subjects, there was no significant difference in plasma 25OHD levels between the sexes.

Figure 3 shows that there was a seasonal fluctuation in plasma 25OHD level, with significantly higher values from June to December compared with January to May, in both patients $(p=0.0001)$ and control subjects $(p=0.03)$. The concentration of 25OHD was significantly $(p<0.05)$ lower

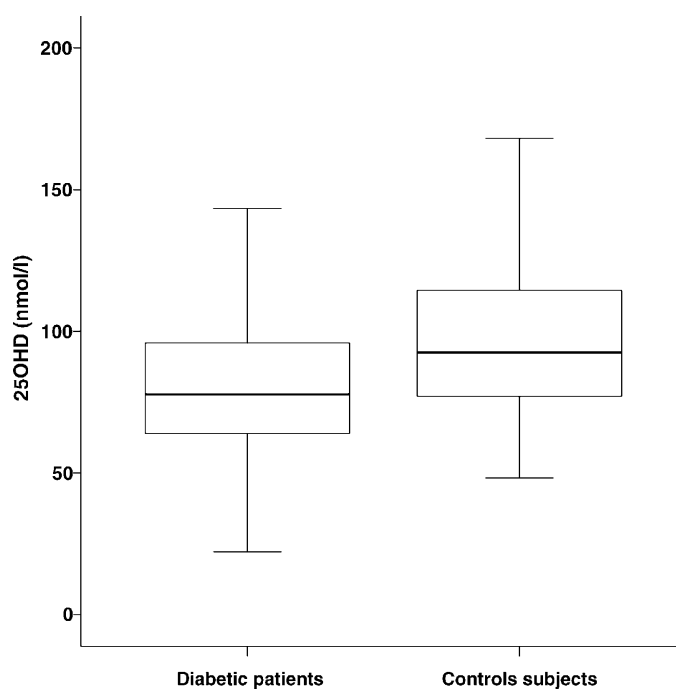

Fig. 2 Box plot of plasma 25OHD levels close to the time of diagnosis in 459 patients with autoimmune type 1 diabetes and 208 control subjects. Data are presented as box-and-whisker plots showing the 10th, 25th, 50th (median), 75th and 90th percentiles in patients compared with control subjects in March, April, May, August, September, October and December. As the seasonal variation of plasma $25 \mathrm{OHD}$ was similar in patients and control subjects, this could not explain differences in levels between patients and control subjects. The concentration of 25OHD was not affected by location of residence (Table 1). Besides the northernmost region $(87.8 \pm 5.1$ vs $89.7 \pm 5.3 \mathrm{nmol} / 1 ; p=0.48)$, all across Sweden plasma 25OHD levels were significantly lower in patients than in control subjects. The month of blood sampling did not differ between patients and control subjects $(p=0.16)$.

At follow-up 8 years after diagnosis

Among patients with blood samples both at diagnosis and at follow-up, the concentration of 25OHD was lower at follow-up ( $86.3 \pm 2.6$ vs $81.5 \pm 2.6 \mathrm{nmol} ; p=0.04)$. There was a positive correlation between the concentrations of $25 \mathrm{OHD}$ at diagnosis and at follow-up $(r=0.57 ; p<0.0001)$. There was no correlation between the concentration of $25 \mathrm{OHD}$ and $\mathrm{HbA}_{1 \mathrm{c}}(r=0.042 ; p=0.62)$. At follow-up, the concentration of 25OHD was significantly lower in men than in women (77.1 \pm 2.8 vs $87.2 \pm 4.5 \mathrm{nmol} / 1 ; p=0.048)$.

\section{Discussion}

Our study showed that the mean 25OHD level at the time of diagnosis was lower among young adults at the time of diagnosis of type 1 diabetes than among control subjects. The levels in the patients were also lower at follow-up

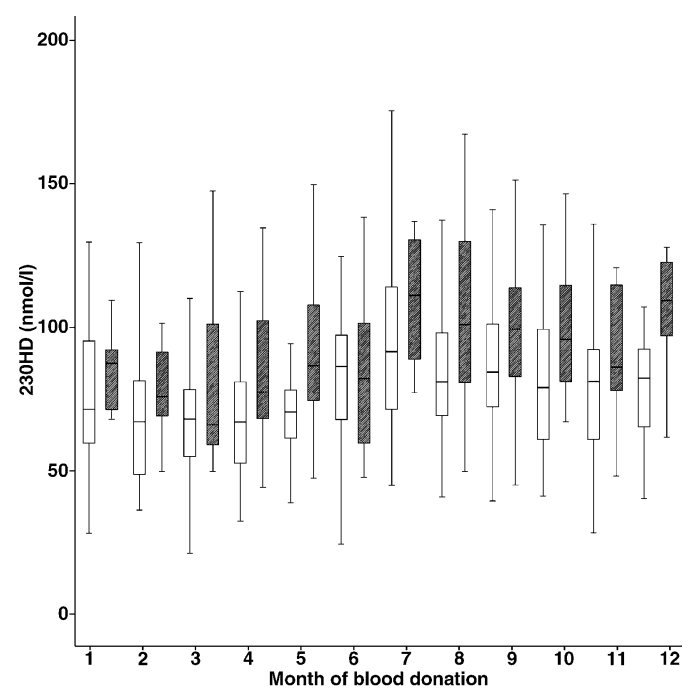

Fig. 3 Box plot of plasma 25OHD levels close to the time of diagnosis in 459 patients with autoimmune type 1 diabetes (white boxes) and 208 control subjects (hatched boxes) with regard to month of blood donation. Data are presented as box-and-whisker plots showing the 10th, 25th, 50th (median), 75th and 90th percentiles 
8 years after diagnosis than at the time of diagnosis. Hence, lower concentrations of $25 \mathrm{OHD}$ were consistent in patients with type 1 diabetes. The clearly lower levels of plasma 25OHD in men than in women with type 1 diabetes was another pertinent finding. The discrepancy in 25OHD levels between patients with type 1 diabetes and control subjects was not due to differences in seasonal fluctuations of 25OHD levels between patients and control subjects, neither did the date for blood sampling deviate between patients and control subjects. Hence, we have no reason to believe that factors related to time of the year or geographical variation explain why our patients with type 1 diabetes had low plasma 25OHD levels.

To avoid misclassification, we employed islet antibodies as objective criteria of type 1 diabetes [26-28]. To our knowledge, this is the first study reporting low plasma 25OHD levels in young adult patients with objective type 1 diabetes. Indeed, $54 \%$ of patients at diagnosis demonstrated levels of $25 \mathrm{OHD}$ below $80 \mathrm{nmol} / \mathrm{l}$, levels regarded as belonging to the interval where vitamin $\mathrm{D}$ deficiency should be considered [29]. The lower levels found at diagnosis compared with control subjects support the idea that vitamin $\mathrm{D}$ deficiency may be an important factor behind the development of type 1 diabetes, perhaps with an immunological background [6-11].

The lower mean levels of 25OHD in diabetic men compared with diabetic women at diagnosis fits with the concept that vitamin D deficiency might be the reason behind the markedly higher incidence of type 1 diabetes among postpubertal men compared with postpubertal women noted in Sweden [14] and in other populations $[30,31]$. The difference in incidence between sexes is not obviously related to HLA [32]. Our study infers that vitamin $\mathrm{D}$ is of interest in this context. There was no significant sex difference regarding plasma 25OHD levels in our 208 control subjects. In a large reference group of more than 6,000 individuals, slightly but significantly higher serum 25OHD values were found in men [33], whereas the opposite was observed in our patients with type 1 diabetes. Further studies are clearly warranted to clarify the role of low vitamin D concentrations as a risk factor for the development of type 1 diabetes among young adults, particularly men. It is of special importance to evaluate serum or plasma samples from prediabetic individuals before and after the development of islet antibodies or type 1 diabetes, as in the Diabetes Trial-type 1 [34] or ENDIT [35]. We lack samples collected before the diagnosis of diabetes in our patients. According to the cross-sectional nature of our study, no information was available on plasma 25OHD levels before diagnosis. Our finding of low plasma 25OHD levels soon after the diagnosis of type 1 diabetes underlines vitamin D deficiency as a factor to consider in the pathogenesis of type 1 diabetes. However, we also noted lower plasma 25OHD levels 8 years after diagnosis compared with levels at diagnosis, and there was no correlation between the concentrations of $25 \mathrm{OHD}$ and $\mathrm{HbA}_{1 \mathrm{c}}$. This indicates that the diabetic state per se is a reason for low 25OHD levels and is not secondary to any hyperglycaemic or insulin-resistant state.

In keeping with this, type 2 diabetes has been linked to vitamin D hypovitaminosis [36]. Vitamin D hypovitaminosis seems to inhibit insulin release [37] and increase insulin resistance $[33,38]$. Indeed, in a pilot study, vitamin $\mathrm{D}_{3}$ treatment improved insulin secretion and insulin resistance in patients with type 2 diabetes [39]. Further studies, however, are apparently needed to establish the role of vitamin $\mathrm{D}$ in type 2 diabetes. It could be that the initiation of type 1 diabetes is related to low vitamin D concentrations whilst the lowering of 25OHD levels during the years after diagnosis is a consequence of disturbed metabolism due to diabetes. Indeed, this may explain why bone density is lower in type 1 than in type 2 diabetes [40].

In conclusion, young adult patients with type 1 diabetes showed lower 25OHD levels soon after their diagnosis compared with control subjects. In addition, 25OHD levels were clearly lower in men than in women with type 1 diabetes. Lower vitamin $\mathrm{D}$ concentrations may contribute to the development of type 1 diabetes, especially in young adult men, who have a particularly high incidence of type 1 diabetes.

Acknowledgements We thank U. Gustavsson, A. Radelius and C. Rosborn for excellent technical assistance. This study was supported by grants from Albert Pålsson Foundation, the Swedish Medical Research Council (72KX-14531), the Swedish Diabetes Association, and Juvenile Diabetes Foundation-Wallenberg Diabetes Research Program (K98-99JD-128B). Reagents for assessment were provided by Nichols Institute Diagnostics (St Clemente, CA, USA).

Duality of interest statement P. Blom is an employee of ElectraBox Diagnostica, Tyresö, Sweden. This company sponsored the assay reagents. There was no duality of interest for any of the other authors.

\section{References}

1. Rewers M, Norris J, Dabelea D (2004) Epidemiology of type 1 diabetes mellitus. Adv Exp Med Biol 552:219-246

2. Mathieu C, Gysemans C, Giulietti A, Bouillon R (2005) Vitamin D and diabetes. Diabetologia 48:1247-1257

3. The EURODIAB Substudy 2 Study Group (1999) Vitamin D supplement in early childhood and risk for Type I (insulindependent) diabetes mellitus. Diabetologia 42:51-54

4. Stene LC, Ulriksen J, Magnus P, Joner G (2000) Use of cod liver oil during pregnancy is associated with lower risk of Type I diabetes in the offspring. Diabetologia 43:1093-1098

5. Hypponen E, Laara E, Reunanen A, Jarvelin MR, Virtanen SM (2001) Intake of vitamin D and risk of type 1 diabetes: a birthcohort study. Lancet 358:1500-1503 
6. Fronczak CM, Baron AE, Chase HP et al (2003) In utero dietary exposures and risk of islet autoimmunity in children. Diabetes Care 26:3237-3242

7. Strugnell SA, Deluca HF (1997) The vitamin D receptor-structure and transcriptional activation. Proc Soc Exp Biol Med 215:223-228

8. Zemunik T, Skrabic V, Boraska V et al (2005) FokI polymorphism, vitamin D receptor, and interleukin-1 receptor haplotypes are associated with type 1 diabetes in the Dalmatian population. J Mol Diagn 7:600-604

9. Zella JB, DeLuca HF (2003) Vitamin D and autoimmune diabetes. J Cell Biochem 88:216-222

10. Kim SH, Cleary MM, Fox HS, Chantry D, Sarvetnick N (2002) CCR4-bearing T cells participate in autoimmune diabetes. J Clin Invest 110:1675-1686

11. Szanya V, Ermann J, Taylor C, Holness C, Fathman CG (2002) The subpopulation of CD4+CD25+ splenocytes that delays adoptive transfer of diabetes expresses L-selectin and high levels of CCR7. J Immunol 169:2461-2465

12. Giarratana N, Penna G, Amuchastegui S, Mariani R, Daniel KC, Adorini L (2004) A vitamin D analog down-regulates proinflammatory chemokine production by pancreatic islets inhibiting $\mathrm{T}$ cell recruitment and type 1 diabetes development. J Immunol $173: 2280-2287$

13. Zerwekh JE (2004) The measurement of vitamin D: analytical aspects. Ann Clin Biochem 41:272-281

14. Blohmé G, Nyström L, Arnqvist HJ et al (1992) Male predominance of type 1 (insulin-dependent) diabetes mellitus in young adults: results from a 5-year prospective nationwide study of the 15-34-year age group in Sweden. Diabetologia 35:56-62

15. Nyström L, Dahlquist G, Östman J et al (1992) Risk of developing insulin-dependent diabetes mellitus (IDDM) before 35 years of age: indications of climatological determinants for age at onset. Int J Epidemiol 21:352-358

16. Östman, Arnquist HJ, Blohmé G et al (1986) Epidemiology of diabetes mellitus in Sweden. Results of the first year of a prospective study in the population age group 15-34 years. Acta Med Scand 220:437-445

17. Landin-Olsson M, Karlsson FA, Lernmark $\AA$, Sundkvist G, and the Diabetes Incidence Study in Sweden Group (1992) Islet cell and thyrogastric antibodies in 633 consecutive 15- to 34-yr-old patients in the Diabetes Incidence Study in Sweden. Diabetes 4:1022-1027

18. Schölin A, Bjorklund L, Borg $\mathrm{H}$ et al (2004) Islet antibodies and remaining beta-cell function 8 years after diagnosis of diabetes in young adults: a prospective follow-up of the nationwide Diabetes Incidence Study in Sweden. J Intern Med 255:384-391

19. Landin-Olsson M, Sundkvist G, Lernmark $\AA$ (1987) Prolonged incubation in the two-colour immunofluorescence test increases the prevalence and titres of islet cell antibodies in type 1 (insulindependent) diabetes mellitus. Diabetologia 30:327-332

20. Borg H, Fernlund P, Sundkvist G (1997) Measurements of antibodies against glutamic acid decarboxylase 65 (GADA): two new ${ }^{125} \mathrm{I}$ assays compared with ${ }^{35}$ SGAD 65 -ligand binding assay. Clin Chem 43:779-785

21. Borg H, Fernlund P, Sundkvist G (1997) Protein tyrosine phosphatase-like protein IA-2-antibodies plus glutamic acid decarboxylase 65 antibodies (GADA) indicates autoimmunity as frequently as islet cell antibodies assay in children with recently diagnosed diabetes mellitus. Clin Chem 43:2358-2363

22. Jeppsson JO, Jerntorp P, Sundkvist G, Englund H, Nylund V (1986) Measurement of haemoglobin A1c by a new liquidchromatographic assay: methodology, clinical utility, and relation to glucose tolerance evaluated. Clin Chem 32:18671872

23. Binkley N, Krueger D, Cowgill CS, Plum L, Lake E, Hansen KE, DeLuca HF, Drezner MK (2004) Assay variation confounds the diagnosis of hypovitaminosis D: a call for standardization. J Clin Endocrinol Metab 89:3152-3157

24. Product insert 2001. Nichols ADVANTAGE 25-hydroxyvitamin D assay. Nichols Institute Diagnostics, San Clemente, CA

25. Antoniucci DM, Black DM, Sellmeyer DE (2005) Serum 25hydroxyvitamin D is unaffected by multiple freeze-thaw cycles. Clin Chem 51:258-260

26. Littorin B, Sundkvist G, Hagopian W et al (1999) Islet cell and glutamic acid decarboxylase antibodies present at diagnosis of diabetes predict the need for insulin treatment. A cohort study in young adults whose disease was initially labelled as type 2 or unclassifiable diabetes. Diabetes Care 22:409-412

27. Borg H, Gottsäter A, Fernlund P, Sundkvist G (2002) A 12-year prospective study of the relationship between islet antibodies and $\beta$-cell function at and after the diagnosis in patients with adult onset diabetes. Diabetes 51:1754-1762

28. Borg H, Arnqvist HJ, Björk E et al (2003) Evaluation of the new ADA and WHO Criteria for Classification of Diabetes Mellitus in young adult people (15-34 yrs) in the Diabetes Incidence Study in Sweden (DISS). Diabetologia 46:173-181

29. Holick, MF (2004) Sunlight and vitamin D for bone health and prevention of autoimmune diseases, cancers, and cardiovascular disease. Am J Clin Nutr 80:1678-1688

30. Gale EA, Gillespie KM (2001) Diabetes and gender. Diabetologia $44: 3-15$

31. Kyvik KO, Nyström L, Gorus F et al (2004) The epidemiology of type 1 diabetes mellitus is not the same in young adults as in children. Diabetologia 47:377-384

32. Graham J, Kockum I, Sanjeevi CB et al (1999) Negative association between type 1 diabetes and HLA DQB1*0602DQA $1 * 0102$ is attenuated with age at onset. Eur J Immunogenet 26:117-127

33. Scragg R, Sowers M, Bell C (2004) Serum 25-hydroxyvitamin D, diabetes, and ethnicity in the Third National Health and Nutrition Examination Survey. Diabetes Care 27:2813-2818

34. Diabetes Prevention Trial-Type 1 Diabetes Study Group (2002) Effects of insulin in relatives of patients with type 1 diabetes mellitus. N Engl J Med 346:1685-1691

35. Gale EA, Bingley PJ, Emmett CL, Collier T (2004) European Nicotinamide Diabetes Intervention Trial (ENDIT): a randomised controlled trial of intervention before the onset of type 1 diabetes. Lancet 363:925-931

36. Isaia G, Giorgino R, Adami S (2001) High prevalence of hypovitaminosis D in female type 2 diabetic population. Diabetes Care 24:1496

37. Norman AW, Frankel JB, Heldt AM, Grodsky GM (1980) Vitamin D deficiency inhibits pancreatic secretion of insulin. Science 209:823-825

38. Chiu KC, Chu A, Go VL, Saad MF (2004) Hypovitaminosis D is associated with insulin resistance and beta cell dysfunction. Am J Clin Nutr 79:820-825

39. Borissova AM, Tankova T, Kirilov G, Dakovska L, Kovacheva R (2003) The effect of vitamin $D_{3}$ on insulin secretion and peripheral insulin sensitivity in type 2 diabetic patients. Int J Clin Pract 57:258-261

40. Petrova NL, Foster AVM, Edmonds ME (2005) Calcaneal bone mineral density in patients with Charcot neuropathic osteoarthropathy: differences between type 1 and type 2 diabetes. Diabet Med 22:756-761 